\title{
Comparison of the Solid State CPMAS and Solution Carbon-13-NMR Spectra of Humic Acids Extracted from .Composted Municipal Refuse
}

\author{
R. Fründ*, F. J. Gonzalez-Vila**, H.-D. Lüdemann*, and F. Martin** \\ * Institut für Biophysik und Physikalische Biochemie, Universität Regensburg, \\ Postfach 397, D-8400 Regensburg, Bundesrepublik Deutschland \\ ** Centro de Edafologia y Biologia Aplicada del Cuarto, C. S. I. C., \\ Apartado 1052, Sevilla, Spain
}

Z. Naturforsch. 42 c, 205-208 (1987); received September 22/November 10, 1986

Humic Acids, C-13-NMR, CPMAS

The solution and CPMAS spectra of humic acids extracted from the composted municipal refuse of three Spanish cities (Sevilla, Granada and Puerto Real) have been obtained at $75.4 \mathrm{MHz}$.

The spectra are discussed qualitatively and the signals assigned to the various chemical structures forming the humic acids.

It is attempted to learn the limits for the quantitative determination of signal areas for the different chemical structures.

It is concluded, that aliphatic- and carbohydrate structures contribute most to these compounds.

\section{Introduction}

In a previous paper [1] the title compounds were characterized by a variety of chemical and physical methods. The latter including solution C-13-NMR spectra at $25.2 \mathrm{MHz}$. Although these spectra revealed considerable details of the chemical structure and composition, the poor signal to noise ratios obtainable with the old spectrometer did not permit the attempt to evaluate the spectra quantitatively. The results given in the following were obtained at 75.4 $\mathrm{MHz}$. Their signal to noise ratio is much higher than found in the old data thus permitting a more detailed discussion of the spectral features. In addition it was possible to vary for the humic acids the experimental conditions for the solution spectra and also to obtain several solid state C-13 CPMAS-spectra. These data will be taken in the following for the better description of the humic acids of the previous publications and in addition they should contribute to the still controversial question, whether C-13-NMR-spectra can be evaluated quantitatively [2].

\section{Experimental}

The preparation of the samples has been given previously [1]. The solution spectra were obtained from $150 \mathrm{mg}$ of the freeze dried humic acids from municipal refuse from Sevilla (HA-S), Puerto Real

Reprint requests to Prof. Dr. H.-D. Lüdemann.

Verlag der Zeitschrift für Naturforschung, D-7400 Tübingen 0341-0382/87/0300-0205\$ \$01.30/0
(HA-PR) and Granada (HA-G) dissolved in $3 \mathrm{ml} 0.5$ normal sodiumhydroxide. They were taken on a Bruker MSL-300 Spectrometer at $75.4 \mathrm{MHz}$ under continuous broad band decoupling conditions with $90^{\circ} \mathrm{RF}$ pulses and pulse delays of $0.5 \mathrm{~s}$. The decoupler power was $100 \mathrm{~W}$ with an attenuation of $25 \mathrm{~dB}$. In the case of HA-S in a second experiment a pulse delay of $5 \mathrm{~s}$ was used in order to study the influence of the different longitudinal relaxation times upon the relative intensities. 30,000 free induction decays were accumulated for each sample. The sweep width was $25 \mathrm{kHz}$, the filter width was set to $30 \mathrm{kHz} .8192$ points were sampled for each FID, yielding an acquisition time of $0.164 \mathrm{~s}$. The solution spectra are calibrated against an external capillary filled with TMS. No attempts were made to correct for magnetic susceptibility effects. The chemical shifts given are judged reliable to $\pm 1 \mathrm{ppm}$. The solid state spectra were obtained at the same frequency on a Bruker CXP-300 under Cross-polarisation-magic-angle-spinning-conditions (CPMAS). The pulse delay was $5 \mathrm{~s}$, the contact time $1 \mathrm{~ms}$. For each spectrum 1000 cycles were accumulated. The sweep width was $31.25 \mathrm{kHz}$, the filter width was set to $37.5 \mathrm{kHz}$. The data table had a size of $1 \mathrm{~K}$. The acquisition time was $0.016 \mathrm{~s}$. The MAS rotation frequency was varied between 4.3 and $5.08 \mathrm{kHz}$.

\section{Results and Discussion}

The solution spectra are compiled in Fig. 1. Although the spectra appear fairly different at first 
Table I. Possible assignments of the $\mathrm{C}-13$ signals in the low field region of the humic acid spectra.

\begin{tabular}{cl}
\hline [ppm] & Possible assignments \\
\hline$\sim 170$ & COOH groups \\
129.5 & arom. C-atoms C-1 in Phenylcumaran \\
119 & arom. C-atoms C-6 in Guajacyl \\
101.6 & $\mathrm{C}-1^{\prime}$ in cellobiose or anomeric C-atom in amylose \\
79.6 & $\mathrm{C}-4$ in cellobiose or C-4 in amylose \\
74.3 & $\mathrm{C}-3, \mathrm{C}-5$ in amylose or cellobiose \\
72.5 & $\beta-2, \mathrm{C}-2^{\prime}$ in cellobiose \\
71.5 & $\alpha-3, \alpha-5, \alpha-2$ in cellobiose \\
60.8 & $\mathrm{C}-6$ in cellobiose \\
$\sim 53$ & $\mathrm{OCH}_{3}$ in carbohydrates or lignine derivatives
\end{tabular}

and polysaccharides. This region is less pronounced than in the soil humic acids [3]. Possible assignments for this range are compiled in Table 1 . The most intense lines in these spectra are seen in the range, where the pure hydrocarbon signals appear. Especially in the HA-S sample many well resolved lines are apparent, that permit interesting conclusions. Table II compiles possible assignments. An inspection of these data makes it obvious, that this region of the spectrum cannot be described by long chain $n$ alkyl groups alone, but that in addition branched alkyl groups have to be considered. The origin of the latter groups remains unknown.

In Fig. 3 the C-13 CPMAS-spectrum of HA-S is given. The most striking difference is, that the spectral region between 150 and 200 ppm which repre-
Table II. Possible assignments of the C-13 signals in the high field region of the humic acid spectra.

\begin{tabular}{ll} 
[ppm] & Possible assignments in linear alkyl groups \\
\hline 13.99 & $\begin{array}{l}\text { methyl groups in long alkane chains, e.g. C-1 in } n \text { - } \\
\text { decane } 14.0, \text { in } n \text {-nonane } 13.9\end{array}$ \\
22.73 & $\begin{array}{l}\text { C-2 in longer alkanes, e.g. } n \text {-pentane } 22.6, n \text { - } \\
\text { nonane } 22.9\end{array}$ \\
29.48 & C-4 in $n$-heptane and $n$-octane 29.3 resp. 29.5 \\
29.80 & C-4 in $n$-nonane and $n$-decane 29.7 resp. 29.8 \\
30.00 & C-5 in $n$-nonane and $n$-decane 30.0 resp. 30.1 \\
32.07 & C-3 in $n$-hexane and longer chains $31.9-32.3$
\end{tabular}

[ppm] Possible assignments in branched alkyl groups

26.69 C-4 in C-2 methylated long chain alkanes, e.g. $2-$ methylheptane 27.2

27.38 methylated $\mathrm{C}-2$ in longer alkanes, e.g. 2methylheptane 27.2

37.97

38.25

C-3 in C-2 methylated long chain alkanes

Literature values taken from: Breitmaier, 1978; Bremser, 1981; Hesse, 1984.

sents the carboxyl groups is much more pronounced in the solid state spectra, than in the solution spectra. These signals, which stem from quarternary carbon atoms are obviously partially saturated in the solution spectra when a pulse delay of $0.5 \mathrm{~s}$ is applied. In additional experiments, the pulse delay for the HA-S

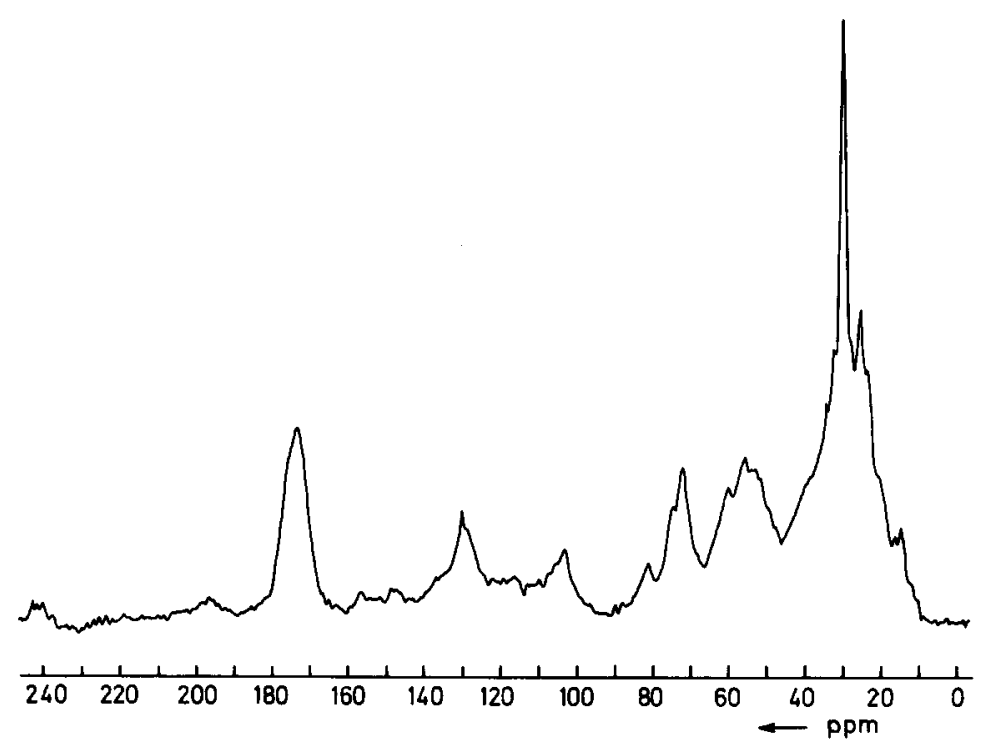

Fig. 3. 75.4 MHz CPMAS spectrum of HAS. Rotation frequency $5.08 \mathrm{KHz}$. 
Table III. Quantitative evaluation of the HA-S spectra.

\begin{tabular}{llllll}
\hline & $\begin{array}{l}\text { Chem. shift groups } \\
\text { [ppm] }\end{array}$ & $\begin{array}{l}10-46 \\
\text { aliphatic }\end{array}$ & $\begin{array}{l}\cdot 46-110 \\
\text { alcoholic }\end{array}$ & $\begin{array}{l}110-150 \\
\text { aromatic }\end{array}$ & $\begin{array}{l}150-200 \\
\text { carboxylic }\end{array}$ \\
\hline \multirow{6}{*}{ CPMAS } & $\begin{array}{l}\text { Rotation frequency } \\
5.08 \mathrm{KHz}\end{array}$ & $42 \%$ & $30 \%$ & $13 \%$ & $15 \%$ \\
& $\begin{array}{l}\text { Rotation frequency } \\
4.64 \mathrm{KHz}\end{array}$ & $42 \%$ & $30 \%$ & $13 \%$ & $15 \%$ \\
& $\begin{array}{l}\text { Rotation frequency } \\
4.30 \mathrm{KHz} \text { TOSS }\end{array}$ & $39 \%$ & $24 \%$ & $18 \%$ & $19 \%$ \\
\hline Solution & $\begin{array}{l}\text { Pulse delay 0.5 s } \\
\text { Pulse delay 5.0 s }\end{array}$ & $\begin{array}{l}57 \% \\
53 \%\end{array}$ & $29 \%$ & $13 \%$ & $1 \%$ \\
\hline
\end{tabular}

a TOSS $=$ total spinning side band suppression.

solution was raised to $5 \mathrm{~s}$. This led to a significant increase of the carboxyl peak. However, a comparison of the resp. numbers in Table III shows, that it is still less intense than in all solid state spectra. No further relative intensity changes were seen, when the pulse delays were raised to $15 \mathrm{~s}$. Saturation of the lines in the solution spectra can thus only in part explain the quantitative difference between CPMAS and solution spectra. Comparison of the spectra in Fig. 1 and 3 reveals, that the solid state spectra show a much lower resolution than the solution spectra. With spectra of the quality of Fig. 3 no detailed assignments of the aliphatic structures is possible.

Finally it was attempted to determine the relative concentrations of the four classes of carbon atoms from the area under the signals. The results are compiled in Table III. Obviously the data of the solution spectra and the CPMAS-spectra show at best qualitative agreement. Even in the totally relaxed solution spectrum (HA-S pulse delay $5 \mathrm{~s}$ ) the carboxyl groups show a greatly reduced contribution compared to the solid state spectra. The aliphatic region on the other

[1] F. J. Gonzalez-Vila and F. Martin, Agric., Ecosystems Environment 14, 267-278 (1985).

[2] C. M. Preston and J. A. Ripmeester, Can. J. Spectrosc. 27, 99-105 (1982).

[3] C. M. Preston and B. A. Blackwell, Soil Science 139, 88-96 (1985).

[4] R. K. Harris, Analyst 110, 649-655 (1985). hand is much more pronounced in the liquid state spectra. Deviations in the intensity of the alcoholic and aromatic groups appear tolerable. Attempts to eliminate spinning side bands by the TOSS-pulseprogram (Total Suppressing of spinning side bands) does lead to significant intensity distortions, showing the hazards of the application of this program to moderatly resolved spectra. It is quite obvious, that the complicated magnetisation transfer occurring in the process of cross polarisation, will render the quantitative analysis of spectra via the determination of relative peak areas fairly hazardous [4]. The situation could probably be a little improved, when systematic variations of the experimental conditions during CPMAS-measurements, such as numbers of contacts per cycle and contact times are varied and their influence on relative intensities studied.

\section{Acknowledgement}

We thank Dr. H. Förster, Bruker, Rheinstetten, for the CPMAS-spectra.

[5] E. Breitmaier and W. Voelter, ${ }^{13} \mathrm{C}$ NMR spectroscopy, Verlag Chemie, 1978.

[6] W. Bremser, E. Ludger, B. Franke, R. Gerhard, and A. Hardt, Carbon-13 NMR spectral data, Verlag Chemie, 1981.

[7] M. Hesse, H. Meier, B. Zeeh, Spektroskopische Methoden in der organischen Chemie, Thieme Verlag, 1984. 